\title{
Correction to: Fuzzy Adaptive Leader-Following Consensus Control for Nonlinear Multi-Agent Systems with Unknown Control Directions
}

\author{
Chang-E Ren ${ }^{1}$ C. L. Philip Chen ${ }^{2}$ Tao Du ${ }^{3} \cdot$ Yong Guan $^{1}$
}

Published online: 4 February 2020

(C) Taiwan Fuzzy Systems Association 2020

\section{Correction to:}

Int J Fuzzy Syst (2019) 21(7):2066-2076

https://doi.org/10.1007/s40815-019-00710-1

In the original publication the author affiliations were inconsistent. The correct affiliations are provided in this correction.

Publisher's Note Springer Nature remains neutral with regard to jurisdictional claims in published maps and institutional affiliations.

The original article can be found online at https://doi.org/10.1007/ s40815-019-00710-1.

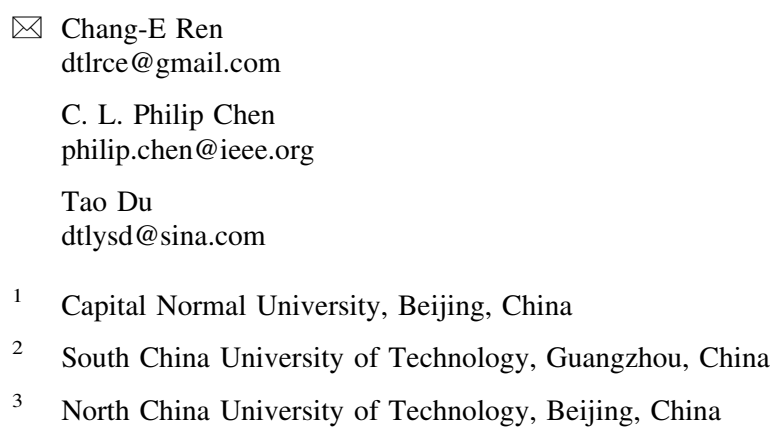

